Brit. F. vener. Dis. (1971) 47, 38

\title{
Detection of the antitrichomonal drug nitrimidazine (Naxogin) in urine
}

\author{
G. D. MORRISON \\ Maudlin Street Clinic, Bristol Royal Hospital
}

AND J. F. W. MCOMIE

School of Chemistry, University of Bristol

For 10 years vaginal trichomoniasis has been treated by oral chemotherapy. Some cases appear not to respond satisfactorily to the drug used, and it is important to know whether or not the patient is taking the drug, and if so, whether or not it is being absorbed from the alimentary tract. A simple method for detecting these drugs in urine may be of use in such cases. Two antitrichomonal drugs in current use are metronidazole ('Flagyl' - May and Baker) and nitrimidazine ('Naxogin' - Carlo Erba). Both are derivatives of 5-nitroimidazole (Figs 1 and 2).<smiles>Cc1ncc([N+](=O)[O-])n1CCO</smiles>

FIG. 1 Chemical formula of metronidazole<smiles>O=[N+]([O-])c1cncn1CCCCCCO</smiles>

FIG. 2 Chemical formula of nitrimidazine

Durel, Couture, and Bassoullet (1967) described a simple method for the detection of metronidazole in urine, which depended on the reduction of the nitro group by zinc in boiling citric acid followed by condensation of the resulting compound with $p$ dimethylaminobenzaldehyde (Ehrlich's reagent) to give a salmon-pink colour on discs of filter paper. The colour was then compared with a set of coloured discs made from standard solutions of metronidazole, thus giving a semi-quantitative measurement of the concentration of the drug. This method detects concentrations of $20 \mathrm{mg}$./litre up to $500 \mathrm{mg}$./litre of metronidazole.
Attempts to apply Durel's method to nitrimidazine were unsuccessful. We therefore devised a very much milder, and much faster, method of reduction. Nitrimidazine is reduced by sodium borohydride $\left(\mathrm{NaBH}_{4}\right)$ in the presence of catalytic amounts of colloidal palladium (prepared in situ from palladous chloride). Reduction is complete in one minute at room temperature. The reaction conditions are so mild that the resulting amine (Fig. $2 \mathrm{NH}_{2}$ in place of $\mathrm{NO}_{2}$ ) is not immediately decomposed but can be condensed with Ehrlich's reagent to give the coloured compound (Fig. 3). This behaves as an acid-base indicator: solutions of it in alkali are orange but become purplish-pink on acidification. Since Ehrlich's reagent is made up in hydrochloric acid, the test solution becomes acidic on the addition of this reagent and the condensation product (Fig. 3) exists in its protonated, purplish-pink form. The intensity of the colour can be measured in a photoelectric colorimeter.

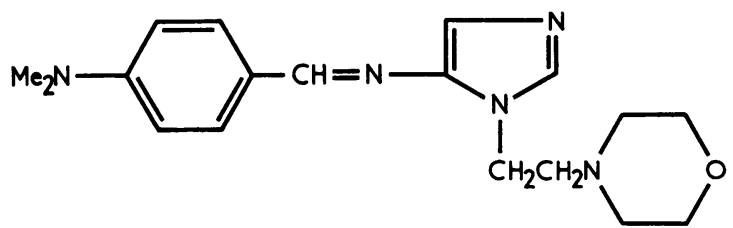

FI G. 3 Chemical formula of nitrimidazine after reduction and condensation with p-dimethylaminobenzaldehyde

The reading is then compared with a calibration curve produced by carrying out a series of reductions on solutions containing known concentrations of nitrimidazine in urine (Fig. 4). Thus our method can be used not only to detect nitrimidazine but to give a semi-quantitative estimate of its concentration in a patient's urine.*

\footnotetext{
*A solution of metronidazole in water on reduction and treatment with Ehrlich's reagent gives a rather similar colour. Doubtless a method for its estimation could be worked out using a procedure similar to
} that described here for nitrimidazine. 


\section{Method}

\section{REAGENTS}

\section{(a) Palladous chloride}

$10 \mathrm{mg}$. of dry palladous chloride are dissolved in $1 \mathrm{ml} .10-\mathrm{N}$ hydrochloric acid with heating, and $99 \mathrm{ml}$. deionized water are then added.

(b) Sodium borohydride

$200 \mathrm{mg}$. of the powder are dissolved in $100 \mathrm{mg}$. deionized water.

(c) Ehrlich's reagent (Sparkman's formula)

$10 \mathrm{~g}$. p-dimethylaminobenzaldehyde are dissolved in $75 \mathrm{ml}$. $10-\mathrm{N}$ hydrochloric acid and the volume is then made up to $150 \mathrm{ml}$. with distilled water.

(d) Lead acetate (Courtonne's reagent)

$30 \mathrm{~g}$. lead acetate is dissolved are $100 \mathrm{ml}$. deionized water.

The solution is filtered immediately before use.

\section{PROCEDURE}

A $3 \mathrm{ml}$.-aliquot of urine is placed in a centrifuge tube (c. $15 \mathrm{ml}$. capacity). $1 \mathrm{ml}$. palladous chloride and $1 \mathrm{ml}$. sodium borohydride are added. Then after 1 minute at room temperature, $0.4 \mathrm{ml}$. lead acetate and $1 \mathrm{ml}$. Ehrlich's reagent are added. The tube is gently shaken to mix the contents and is then placed in a water-bath at $37^{\circ} \mathrm{C}$. for 5 minutes. At the end of this time the tube is removed and the contents are centrifuged at 3,000 r.p.m. for 5 minutes. The supernatant fluid is pipetted off and placed in the colorimeter cuvette. A blank, consisting of urine with all the reagents except sodium borohydride (which is replaced by distilled water), is made and is used to set the zero reading of the colorimeter. We have used an EEL photoelectric colorimeter with an OGR1 green filter.

\section{Discussion}

There are two sources of error in the method.

(1) Bubbles of hydrogen tend to form in the colorimeter cuvette and thus give a falsely high reading. The bubbles should be dislodged by gently tapping the side of the tube.

(2) Although most of the compounds in urine which are likely to interfere with the colour production are removed by the addition of lead acetate (see Method), we have found that blood or blood pigments if present in the urine will react with Ehrlich's reagent to give reddish pigments and hence spuriously high readings in the colorimeter.

It will be obvious that, in any one patient, the concentration of drug detected in urine at any one time depends on the rate of urine formation at that time. We suggest that, in a concentrated urine giving a reading of drug concentration in excess of 100 mg./litre, the urine should be diluted.

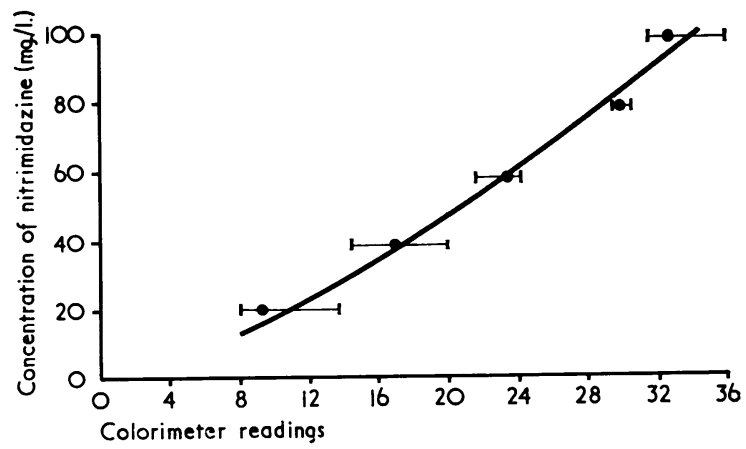

FIG. 4 Graph showing experimental results

We strongly advise that three aliquots should be taken of any urine being examined and that the concentration of the drug present in each aliquot be determined separately. We take the average of the three readings.

We also advise that anyone using this method should construct a calibration curve for his owr colorimeter. As the light absorption of the coloures compound formed does not vary in an exactly linear relationship with the concentration of the compound present (Fig. 4), it is necessary to determine the colorimeter readings at several known concentrations of nitrimidazine in urine.

One of us (G.D.M.) has used this method of estimation satisfactorily on a number of patients.

\section{Summary}

A rapid semiquantitative method of estimating the presence of nitrimidazine in urine is described, using sodium borohydride as the reducing agent, colloidal palladium as catalyst, and Ehrlich's reagent to produce a coloured condensation compound. The intensity of the colour is read in a photoelectric colorimeter. Possible sources of error are indicated.

We wish to thank Dr. H. R. Cayton for making available the facilities of the Bristol laboratory of the Public Health Laboratory Service, Mr. R. Shannon for technical advice, Dr. A. Marus and Carlo Erba Ltd. for samples of nitrimidazine, May and Baker Ltd. for samples of metronidazole, and Dr. A. Tinkler, Director of the Maudlin Street Clinic, for his encouragement.

\section{Reference}

Durel, P., Couture, J., and Bassoullet, M. T. (1967) Brit. F. vener. Dis., 43, 111 